\title{
New Avenues of Bioenergy Production from Plants: Green Alternatives to Petroleum
}

\author{
Chandrashekhar P. Joshi ${ }^{1 *}$ and Akula Nookaraju ${ }^{2}$ \\ ${ }^{1}$ Biotechnology Research Center, School of Forest Resources and Environmental Science, Michigan Technological University, Houghton, MI 49931, USA \\ ${ }^{2}$ Department of Bioenergy Science and Technology, Chonnam National University, South Korea
}

\begin{abstract}
Depleting fossil fuel reserves and growing demand for energy have necessitated the renewed search for alternative energy resources such as plants and algae. The first generation biofuels were produced from starch and sugars (bioethanol) and from seed oils (biodiesel). These, however, soon became negatively associated with issues such as competition with food supply, significant land-use changes and many other ethical issues. The production of second generation biofuels from lignocellulosic materials from grasses and trees requires high-input technologies involving extensive pre-treatments and expensive cellulolytic enzymes, adding to the high costs of second generation bioethanol. Recently, third generation biofuels derived from microalgae have attracted the attention of plant biologists and industrialists due to fast growth rate, high $\mathrm{CO}_{2}$ fixation ability and high production capacity of microalgae. Now, there also exists a promising fourth generation of biofuels on the horizon which involves metabolically-engineering of plants and algae possessing traits such as high biomass yield, improved feedstock quality and high $\mathrm{CO}_{2}$ fixation. Various novel processes such as gasification, pyrolysis and torrefaction are also being pursued for improving the total energy yield from plant biomass. Recent investigations in biofuels area are aimed at developing plants with improved feedstock quality, developing recombinant enzymes for rapid cell wall degradation, improving capacity of microorganisms for efficient fermentation, and discovering novel methods for efficient utilization of plants and algae for producing biofuels.
\end{abstract}

Keywords: Biofuels; Cellulose; Carbon capture and storage; Microalgae; Pyrolysis; Triacylglycerols

\section{Introduction}

In recent years, biofuels derived from plant biomass have gained increased public and scientific attention and scrutiny, driven by factors such as unpredictable oil price fluctuations, increased energy demands and the need for improved energy security. Biofuels are basically divided into primary (e.g. fuel wood) and secondary fuels. The secondary biofuels can be categorized into at least four generations on the basis of their processing technologies, types of feedstock used and/or their level of development [1]. The first generation biofuels produced from starch and sucrose materials of food crops are associated with several negative ethical issues such as "food versus fuel" debate. The second generation biofuels are produced from lignocellulosic feedstock (bioethanol) from grasses and trees. However, converting the woody biomass into fermentable sugars still requires high input technologies involving extensive pre-treatments and expensive enzymes, significantly adding to higher cost of second generation biofuels [2]. Second generation biodiesel is derived from seed oils of non-conventional crops such as Jatropha. Of late, third generation biofuels derived from algae are becoming promising alternative to first and second generation biofuels due fast growth rate, $\mathrm{CO}_{2}$ fixation ability and high production capacity of algae. Recently, fourth generation biofuels are also actively considered that involve metabolically-engineered plants and algae possessing useful traits such as high biomass yield, improved feedstock quality and high $\mathrm{CO}_{2}$ fixation ability. This review summarizes recent innovations in the field of biofuels: production of bioethanol from plants and algae; biodiesel from plant oils produced in vegetative parts rather than seeds and from microalgae; production of recombinant enzymes for cell wall degradation in transgenic organisms; and the recent efforts towards efficient utilization of plant biomass by increasing the feedstock convertibility.

\section{Production of Ethanol from Plant Biomass}

Bioethanol is the most widely used liquid biofuel. Bioethanol is produced by converting sugars into ethanol via yeast fermentation. These sugars can come directly from crops such as sugarcane or sugar beets, indirectly from starch derived from corn and wheat, or through cellulose from biomass. The global production of ethanol in 2011 was 84.5 billion liters representing about $4 \%$ of the global gasoline consumption [3]. The United States is the largest producer of bioethanol, accounting for nearly $47 \%$ of global bioethanol production, followed by Brazil (37\%). About $60 \%$ of global bioethanol production comes from sugarcane and sugar beet. Brazil exclusively uses sugarcane for bioethanol production while the United States and Europe mainly use starch from corn (USA), and from wheat and barley (Europe) [4]. The most serious concern related to first generation biofuels is that they compete with agriculture for arable land and other resources. Plus there is a food versus fuel debate that is raging recently questioning ethics of diversion of food materials for ethanol production.

Second generation biofuels (bioethanol) are produced from cellulose present in plant cell walls. By not using food crops as the source of sugars, second generation bioethanol production is more sustainable and has a lower impact on food production. Cellulose is a

*Corresponding author: Chandrashekhar P. Joshi, Biotechnology Research Center, School of Forest Resources and Environmental Science, Michigan Technological University, Houghton, Ml 49931, USA; E-mail: cpjoshi@mtu.edu

Received November 05, 2012; Accepted November 27, 2012; Published December 02, 2012

Citation: Joshi CP, Nookaraju A (2012) New Avenues of Bioenergy Production from Plants: Green Alternatives to Petroleum. J Pet Environ Biotechnol 3:134. doi:10.4172/2157-7463.1000134

Copyright: ( 2012 Joshi CP, et al. This is an open-access article distributed under the terms of the Creative Commons Attribution License, which permits unrestricted use, distribution, and reproduction in any medium, provided the original author and source are credited. 
linear, insoluble biopolymer composed of repeating $\beta$-D-glucopyranose residues linked by $\beta-1,4$-glycosidic bonds. Cellulose is embedded in a heterogeneous matrix composed of hemicellulose and lignin, which makes it recalcitrant to enzymatic hydrolysis. As a result, converting the woody biomass into fermentable sugars (saccharification) requires costly technologies involving pretreatments and use of special lignocellulolytic enzymes. The relative proportion of cell wall components and cellulose properties influence cell wall digestibility. In two earlier reports by Harris et al. [5,6], Arabidopsis primary cell wall mutants with a decreased cellulose relative crystallinity index (RCI) showed increased sugar-release efficiency, indicating a negative correlation between cellulose crystallinity and saccharification $[5,6]$. These studies indicate the possibility of generating transgenic plants expressing modified proteins involved in cellulose synthesis that increase the preferential accumulation of less crystalline cellulose for more efficient conversion of cellulose feedstock into simple sugars [7].

The second most abundant component in plant cell walls is xylan which is a type of hemicellulose. It is composed of a $\beta(1,4)$-linked D-xylosyl (Xyl) backbone with multiple side branches. Manipulation of genes involved in xylan backbone synthesis or substitutions enhances the relative proportion of cellulose and/or improves the enzymatic saccharification of wood as observed in GlucUronic acid substitution of Xylans (GUX) mutants [8] and irx15 and irx15 irx15L mutants of Arabidopsis [9]. The change in xylan quantity and substitution has commercial significance for increasing the efficiency of bioethanol production by increasing the biomass saccharification efficiency as observed in RNAi lines of poplar with reduced expression of PoGT47C and $G T 43 B[10,11]$

Lignin is the third most abundant cell wall component. It imparts mechanical strength to the plant but resists cellulose digestibility. The amount of lignin in cell walls negatively influences cell wall digestibility and sugar release efficiency as observed in natural variants of undomesticated Populus trichocarpa trees [12]. Several studies have been reported which aimed at improved feedstock digestibility for increased bioethanol production by manipulating lignin pathway. The first study was reported by Chen and Dixon [13], where transgenic alfalfa lines with altered lignin levels showed enhanced sugar release indicating the negative correlation between lignin levels and accessibility of cellulose to enzymatic hydrolysis. Following this, several studies were reported in crops like tobacco, maize, switchgrass, poplar and sugarcane where down regulation of lignin pathway genes resulted in improved saccharification efficiencies with a potential increase in bioethanol production from transgenic plant materials [7].

\section{Possibilities of Ethanol Production from Plant Proteins}

Biofuels are currently produced from carbohydrates and lipids derived from plants and animals. Due to difficulties in hydrolysis, proteins have not yet been exploited for biofuel production. Proteins could possibly be used for preparation of ethanol by cleaving the amino groups from individual amino acids followed by yeast fermentation. Using a similar strategy, Huo et al. [14] recently generated transgenic Escherichia coli that can deaminate protein hydrolysates, enabling the cells to convert proteins to C4 and C5 alcohols at $56 \%$ of the theoretical yield. This study demonstrated the novel possibility of using proteins from plants and animals as feedstock for bioethanol production.

\section{Third Generation Biofuels}

Third generation biofuels, also termed advanced biofuels, are produced from fast growing microalgae and are potential replacements for conventional fuels. Microalgae are being promoted as an ideal third generation biofuel feedstock because of their rapid growth rate, low requirements for fertilizer and land use, high $\mathrm{CO}_{2}$ fixation ability, lack of competition with food crops, and production possibilities on non-arable land. Microalgae have broad bioenergy potential as they can be used to produce biodiesel and bioethanol. For example, Chlorella vulgaris has been considered as a potential raw material for bioethanol production because it can accumulate high levels of starch [15]. Production of bioethanol by using microalgae can also be performed via self-fermentation. As reported by Ueno et al. [16], dark fermentation of marine green algae Chlorococcum littorale at $30^{\circ} \mathrm{C}$ could produce $450 \mu \mathrm{mol}$ of ethanol g-1 biomass. Chlorella protothecoides is another microalga that can accumulate lipids up to $55.2 \%$ of its biomass under favorable conditions [17]. In a recent study, overexpression of two Arabidopsis diacyl glycerol acyl transferase 2 (AtDGAT2) homologs from green algae Chlamydomonas reinhardtii, CrDGAT2-1 and CrDGAT2-5, led to a 27.25 and $48.25 \%$ increase in oil content, respectively, in transgenic $C$. reinhardtii at 6 days of growth [18]. All of these strains of microalgae are potential candidates for supplementing our growing energy demands by producing bioethanol and/or biodiesel.

Recently, research groups at the Russian Academy of Sciences in Moscow screened various filamentous fungi for their ability to accumulate lipids. They found that a single-celled fungus Cunninghamella japonica could accumulate $7 \mathrm{gl}^{-1}$ lipids in their total biomass of $16 \mathrm{~g}$ [19]. This fungus can be exploited commercially for producing an environmentally-safe low-cost biodiesel.

\section{Fourth Generation Biofuels}

Fourth generation biofuels are a step ahead from third generation biofuels. In fourth generation systems, the feedstock is tailored to improve the processing efficiency and designed to capture more carbon dioxide than normal. The processing methods are also coupled to "carbon capture and storage (CCS)" technologies which funnel the generated carbon dioxide into geological formations or mineral storage systems. In this way, fourth generation biofuels are better at reducing greenhouse gas emissions than other generation biofuels. Fourth generation biofuel crops include high biomass crops, trees with increased carbon storage capacity, drought-tolerant energy crops, grass species that are able to grow on acidic soils, and new plants with particular properties catering to a specific bioconversion process (e.g. low lignin trees, maize with embedded enzymes for rapid conversion). Recent examples include designed Eucalyptus trees with a low-lignin content which allows for easier conversion into cellulosic ethanol.

\section{Biobutanol Production from Plants}

Biobutanol, sometimes called biogasoline, is the second generation alcoholic fuel possessing a higher energy density (20\% higher than ethanol) and lower volatility than ethanol. It is currently used as an industrial solvent in wood finishing products. Since biobutanol is more chemically similar to gasoline, it can be used as $100 \%$ fuel or blended with gasoline or diesel at $10 \%$. Biobutanol is made via fermentation process (mediated by Clostridium acetobutylicum) from sugars released from sucrose, starch and plant biomass. Owing to several advantage over bioethanol, many companies around the globe started investing in research and technology development for efficient production of biobutanol from plants. DuPont (USA) and British Petroleum (UK) plan to make biobutanol the first product of their joint effort to develop, produce, and market next-generation biofuels [20]. In Europe the Swiss company Butalco is developing genetically modified yeasts 
for the production of biobutanol from cellulosic materials. Efforts are being made for identification of new efficient strains of bacteria and improvement of existing bacteria for efficient conversion of sugars to butanol. Researchers at Tulane University discovered a Clostridium strain named "TU-103", which can convert nearly any form of cellulose into butanol, and is the only known strain of Clostridium that can do fermentation in the presence of oxygen [21].

\section{Biodiesel from Non-Seed Tissues of Plants}

Biodiesel is produced from plant oils or animal fats using transesterification. Chemically, they are fatty acid methyl (or ethyl) esters (FAMEs). Fuels from feedstocks such as soybean, palm, canola and rapeseed are considered first generation biodiesels as they were the first crops to be tested for biodiesel. Alternatively, second generation biodiesel is obtained from non-food crops such as Jatropha and pongamia. As mentioned in earlier sections, microalgae are being considered as a feedstock for the production of third generation biodiesels. With the advent of genetic engineering, several studies have been initiated to engineer increased oil production in seeds of many crop plants for bioenergy.

Plant oils are primarily composed of various triacylglycerols (TAGs) which consist of three fatty acid chains (usually 18 or 16 carbons long) esterified to glycerol. These fatty acyl chains are chemically similar to the aliphatic hydrocarbons found in petrol and diesel. However, most plant TAGs are highly viscous thus not completely combustible. To overcome this limitation, TAGs are converted to less viscous fatty acid methyl esters by esterification with methanol. Knowing the importance of TAGs for biofuel production, attempts have been made to specifically overaccumulate TAGs in vegetative tissues. This would enhance the total bioenergy yield per plant or per unit area of land. The first attempt made recently in this direction by expressing AtDGAT1 under a strong leaf-specific RbcS promoter [22]. The transgenic tobacco plants showed up to a 20 -fold increase in TAG accumulation in leaves with a $100 \%$ increase in fatty acids yields [22]. In another recent study, overexpression of WRINKLED 1 (WRI1) gene in transgenic Arabidopsis resulted in 160 - 180\% increase in total TAG accumulation in leaves [23]. These studies indicate a potential approach for increasing the energy density of plant biomass by engineering plants to accumulate TAGs in vegetative tissues such as leaves, stems and roots. Engineering tobacco to accumulate more oils in leaves is a potential alternative for the production of biodiesel. However, in the case of bioenergy trees like poplar, genetic engineering to accumulate oils in stems will have an increased impact on bioenergy production given that after oil extraction the same stems can be used for bioethanol production. Other recent TAG-focused strategies include increasing the accumulation of TAGs in plant tissues by blocking the sucrose to starch conversion in chloroplasts [23] or blocking the degradation of TAGs in peroxisomes.

\section{Novel Processes for Improved Bioenergy Yield from Plant Biomass}

In general, lignocellulosic feedstocks are subjected to dilute acid or alkali pretreatment followed by enzymatic saccharification to release simple sugars. These sugars are finally converted to alcohols by yeast fermentation. There are other novel ways of enriching plant feedstock to produce high energy fuel wood, such as gasification and pyrolysis. Gasification allows for the production of very clean synthetic biofuels, by liquefying the syngas via Fischer-Tropsch synthesis - a combined pathway known as 'biomass-to-liquids' (BTL). Pyrolysis is the decomposition of biomass in the absence of oxidizing agents, usually at around $300-650^{\circ} \mathrm{C}$. In fast pyrolysis, biomass is rapidly heated (450$600^{\circ} \mathrm{C}$ ) in the absence of air to yield a heavy fuel oil type liquid, biooil or pyrolysis oil that can be further refined into a range of designer fuels or used as such. Torrefaction is similar to pyrolysis but occurs at a lower temperature (around $200-320^{\circ} \mathrm{C}$ ). Both techniques utilize the decomposition of biomass to produce valuable products such as coke, syngas, charcoal and lighter hydrocarbons like gasoline. Syngas, a mixture of carbon monoxide, hydrogen and other hydrocarbons, is produced by partial combustion of biomass under low oxygen environment. Syngas may be burned directly in internal combustion engines, turbines or high-temperature fuel cells. Another derivative of solid biofuel is biochar, which is produced by biomass pyrolysis and can substitute for wood charcoal.

Methane, derived from biogas (a mixture of $\mathrm{CH}_{4}$ and $\mathrm{CO}_{2}$, minor amounts of water, $\mathrm{H}_{2} \mathrm{~S}$ and other gases), is another gaseous biofuel that could be directly used without modifications of the engines. However, purification of methane from biogas adds to the high cost of the fuel. Methane or natural gas is already in use as a fuel for cars. Apart from methane, hydrogen $\left(\mathrm{H}_{2}\right)$ can also serve as a fuel in Otto-type combustion engines and in fuel cells. Hydrogen is produced as a byproduct during the conversion of biomass to synthesis gas (a mixture of mostly CO and $\mathrm{H}_{2}$ ), from which $\mathrm{H}_{2}$ is further purified and compressed. Hydrogen is also formed during photosynthesis, fermentation and nitrogenasemediated production. Recent breakthrough in this field is seen with highly efficient hydrogen production from any type of biodegradable organic matter in electrohydrogenic reactors with mixed cultures of bacteria [24].

\section{Enzymes in Biofuel Production}

Efficient enzymatic hydrolysis of biomass remains a bottle neck in economic production of cellulosic ethanol owing to the high cost of hydrolyzing enzymes (cellulases, xylanases and ligninases). Presently, these enzymes are extracted from bacteria and fungus. However extraction of enzymes from these conventional sources is quite expensive. Easy and enhanced production of cellulases and xylanases with higher specific activity at high temperatures and specific $\mathrm{pH}$ can be achieved through protein engineering in bacteria. Alternatively, production costs of these enzymes can be reduced by expressing them in crop plants [25]. Many researchers have produced cellulases and xylanases in several crop plants like barley, tobacco, maize, wheat, etc. [26]. In-planta expression of cell wall degrading enzymes in plants will lead to self-deconstruction of plant cell walls to generate monomeric sugars for fermentation resulting in the economic efficiency of the cellulosic biofuel production. To avoid self-deconstruction by the expressed enzymes during growth, it is also important to express them during appropriate developmental stages, rather than over the entire lifetime of the plants. In addition to lignocellulose-degrading enzymes, there are also enzymes involved in remodeling the cell wall, referred as expansins, which facilitate easy feedstock digestibility. Expansins increase the extensibility and relax the tension of plant cell walls breaking hydrogen bonds between cellulose fibers or between cellulose and other polysaccharides through a non-enzymatic mechanism.

\section{Utilization of Bioethanol and Biodiesel as Transportation Fuels}

Plant and algae-derived ethanol can be used as a pure fuel or as a mixture with gasoline in certain proportions to replace conventional fuels, without affecting the performance of the machine. Being an 
oxygenated fuel (contains 35\% of oxygen), use of bioethanol reduces exhaust emissions such as $\mathrm{CO}$ and unburned hydrocarbons in to atmosphere [27]. The most common blend of bioethanol with petrol is gasohol, also called E10 containing $10 \%$ bioethanol and $90 \%$ gasoline. E10 could be burned in the internal combustion engines (ICEs) of most modern cars [28]. Bioethanol could also be used in blended fuels such as E85 (containing $85 \%$ ethanol and 15\% gasoline). The biologically produced ethanol contains about $5 \%$ water and by using an appropriate emulsifier this hydrated ethanol could be mixed with diesel. A mixture of hydrated ethanol with diesel with the emulsifier is called diesohol. This contains $84.5 \%$ diesel, $15 \%$ hydrated ethanol and $0.5 \%$ of emulsifier [28]. In Brazil, ethanol is used as clean or as gasohol (24\% ethanol and $76 \%$ gasoline) [27]. While in the European Union, according to the EN228 standard, bioethanol could be used as a $5 \%$ blend with gasoline.

On the other hand, biodiesel is the most common biofuel in Europe. Pure biodiesel (B100) is the lowest emission fuel. Biodiesel can be used in any diesel engine when mixed with diesel. Biodiesel is safe to handle and transport as it is biodegradable and has a high flash point compared to diesel [29]. To use for B100 fuel, vegetable oil must be heated to reduce its viscosity to that of diesel for efficient combustion. In many European countries, a 5\% biodiesel blend is widely used and is available at many gas stations [29]. Alternatively, oils and fats can be hydrogenated to give a diesel substitute with a high cetane number, lower levels of aromatics and sulfur and no oxygen. Hydrogenated oils can be blended with diesel in all proportions.

\section{Concluding Remarks}

Given that first generation biofuels are negatively associated with food production and utilization issues and second generation biofuels have high input costs, biofuels from algal cultures seem to be the most promising fuels for the future. Current technologies to produce ethanol from cellulose utilize simultaneous saccharification and fermentation (SSF) or simultaneous saccharification and co-fermentation (SSCF), which require extensive pretreatments and expensive cellulolytic enzymes. Consolidated bioprocessing (CBP), where cellulose production, substrate hydrolysis, and fermentation are accomplished in a single step by microorganisms that express cellulolytic (and hemicellulolytic) enzymes, offers the potential for lower biofuel production costs and higher conversion efficiencies.

Considering that bioethanol costs more to produce than fossil gasoline, governments should enact special policies to encourage the production and use of bioethanol in the transportation sector. However, with the development of more efficient and cheaper saccharification and fermentation technologies, biofuels could be a cost-effective alternative in the near future in many developing countries. Future research for improving the generation of biofuels should focus on improving: cellulose and cell wall properties of plants, enzymes for cellulose and hemicellulose digestion, strains for CBP, lignin degrading enzymes/microbes, strains for pentose fermentation, and lipases for efficient oil transesterification.

\section{Acknowledgements}

This work was supported by funding from the World Class University project of the Ministry of Science and Technology of Korea (R31-2009-000-20025-0). We also wish to thank Ms. Sandra Hubscher for critical reading of this manuscript.

\section{References}

1. Nigam PS, Singh A (2010) Production of liquid biofuels from renewable resources. Progress in Energy and Combustion Science 37: 52-68.
2. Brennan $L$, Owende $P(2010)$ Biofuels from microalgae-A review of technologies for production, processing, and extractions of biofuels and co-products. Renewable and Sustainable Energy Reviews 14: 557-577.

3. RFA FO Lichts (2012) World ethanol and bioenergy reports. Vol 10. Renewable Fuel Assoaciation, USA.

4. Linde M, Galbe M, Zacchi G (2008) Bioethanol production from non-starch carbohydrate residues in process streams from a dry-mill ethanol plant. Bioresour Technol 99: 6505 - 6511.

5. Harris D, Stork J, DeBolt S (2009) Genetic modification in cellulose-synthase reduces crystallinity and improves biochemical conversion to fermentable sugar. Glob Change Biol Bioener 1: 51-61.

6. Harris DM, Corbin K, Wang T, Gutierrez R, Bertolo AL, et al. (2012) Cellulose microfibril crystallinity is reduced by mutating $\mathrm{C}$-terminal transmembrane region residues CESA $1^{\mathrm{A} 903 \mathrm{~V}}$ and $\mathrm{CESA}{ }^{3 \mathrm{~T} 9421}$ of cellulose synthase. Proc Natl Acad Sci U SA 109: 4098-4103.

7. Nookaraju A, Pandey SK, Bae HJ, Joshi CP (2012) Designing cell walls for improved bioenergy production. Mol Plant Advance Publication.

8. Mortimer JC, Miles GP, Brown DM, Zhang Z, Segura MP, et al. (2010) Absence of branches from xylan in Arabidopsis gux mutants reveals potential for simplification of lignocellulosic biomass. Proc Natl Acad Sci U S A 107: 1740917414.

9. Brown D, Wightman R, Zhang Z, Gomez LD, Atanassov I, et al. (2011) Arabidopsis genes IRREGULAR XYLEM (IRX15) and IRX15L encode DUF579-containing proteins that are essential for normal xylan deposition in the secondary cell wall. Plant J 66: 401-413.

10. Lee C, Teng Q, Huang W, Zhong R, Ye ZH (2009) Downregulation of PoGT47C expression in poplar results in a reduced glucuronoxylan content and an increased wood digestibility by cellulase. Plant Cell Physiol 50: 1075-1089.

11. Lee C, Teng Q, Zhong R, Ye Z-H (2011) Molecular dissection of xylan biosynthesis during wood formation in poplar. Mol Plant 4: 730-747.

12. Studer MH, DeMartini JD, Davis MF, Sykes RW, Davison B, et al. (2011) Lignin content in natural Populus variants affects sugar release. Proc Natl Acad Sci U S A. 108: 6300-6305.

13. Chen F, Dixon RA (2007) Lignin modification improves fermentable sugar yields for biofuel production. Nat Biotechnol 25: 759-761.

14. Huo Y-X, Cho KM, Rivera JGL, Monte E, Shen CR, et al. (2012) Conversion of proteins into biofuels by engineering nitrogen flux. Nat Biotechnol 29: 346-351.

15. Hirano A, Ueda R, Hirayama S, Ogushi Y (1997) CO2 fixation and ethanol production with microalgal photosynthesis and intracellular anaerobic fermentation. Energy 22:137-142.

16. Ueno Y, Kurano N, Miyachi S (1998) Ethanol production by dark fermentation in the marine green alga, Chlorococcum littorale. J Ferment Bioeng 86: 38-43.

17. Miao XL, Wu QY (2004) High yield bio-oil production from fast pyrolysis by metabolic controlling of Chlorella protothecoides. J Biotechnol 110: 85-93.

18. Deng X-D, Gu B, Li Y-J, Hu X-W, Guo J-C, et al. (2012) The roles of acyl-CoA: diacylglycerol acyltransferase 2 genes in the biosynthesis of triacylglycerols by the green algae Chlamydomonas reinhardtii. Mol Plant 4: 945-947.

19. Sergeeva YE, Galanina LA, Andrianova DA, Feofilova EP (2008) Lipids of filamentous fungi as a material for producing biodiesel fuel. Appl Biochem Microbiol 44: 523.

20. Reardon M (2008) Partnership Sees Value in 1-Butanol and Other Higher Octane Isomers. Press release.

21. Ray KH (2011) "Cars Could Run on Recycled Newspaper, Tulane Scientists Say". Tulane University news webpage. Tulane University. Retrieved March 14 2012

22. Andrianov V, Borisjuk N, Pogrebnyak N, Brinker A, Dixon J, et al. (2010) Tobacco as a production platform for biofuel: overexpression of Arabidopsis DGAT and LEC2 genes increases accumulation and shifts the composition of lipids in green biomass. Plant Biotechnol J 8: 277-287.

23. Sanjaya, Durrett TP, Weise SE, Benning C (2011) Increasing the energy density of vegetative tissues by diverting carbon from starch to oil biosynthesis in transgenic Arabidopsis. Plant Biotechnol J 9: 874-883. 
Citation: Joshi CP, Nookaraju A (2012) New Avenues of Bioenergy Production from Plants: Green Alternatives to Petroleum. J Pet Environ Biotechnol 3:134. doi:10.4172/2157-7463.1000134

Page 5 of 5

24. Cheng S, Logan BE (2007) Sustainable and efficient biohydrogen production via electrohydrogenesis. Proc Natl Acad Sci U S A104: 18871-18873.

25. Sticklen M (2008) Plant genetic engineering for biofuel production: towards affordable cellulosic ethanol. Nat Rev Genet 9: 433-443.

26. Sainz MB (2009) Commercial cellulosic ethanol: The role of plant-expressed enzymes. In Vitro Cell Dev Biol-Plant 45: 314-329.
27. Balat M, Balat M (2009) Political, economic and environmental impacts of biomass-based hydrogen. Intl J Hydrogen Energ 34: 3589-3603.

28. Demirbas A (2008) Biofuels sources, biofuel policy, biofuel economy and global biofuel projections. Energy Conversion and Management 49: 2106-2116.

29. Biofuels Facts. Hempcar.org. 